\title{
Determinants of Domestic Food Price Differentials: Constraints for Intra-Uganda Trade
}

\author{
Isaac M. B. Shinyekwa ${ }^{1} \&$ Alex Thomas Ijjo ${ }^{1}$ \\ ${ }^{1}$ Department of Trade, Regional Integration and Multilateral Arrangements at the Economic Policy Research \\ Center, Makerere University, Kampala, Uganda \\ Correspondence: Isaac M. B. Shinyekwa, Department of Trade, Regional Integration and Multilateral \\ Arrangements at the Economic Policy Research Center, Makerere University, PO Box 7841, Kampala, Uganda. \\ E-mail: ishinyekwa@eprcug.org
}

Received: June 1, 2015 Accepted: July 2, 2015 Online Published: January 26, 2016

doi:10.5539/jsd.v9n1p286

URL: http://dx.doi.org/10.5539/jsd.v9n1p286

\begin{abstract}
The paper estimates the determinants of price differentials across 79 districts in Uganda. In the framework of the law of one price, we examine the hypothesis that the spatial price differentials are at least partly influenced by transportation and other transaction costs, infrastructural constraints, productivity and commodity output shocks and the purchasing power of households. The study notes the wide range of price differences across the country, which to a large extent can be attributed to the interaction between remoteness and the quality of physical infrastructure. The effect of income per capita on price differentials is relatively uniform across commodities. The findings point towards the importance of strengthening the capacities of farmers and their productivity as a means to improve their livelihoods and foster more efficient markets with faster supply responses to changes in prices. The findings further emphasize the significance of spatial dimension and infrastructure conditions in Uganda, suggesting that infrastructural development must be a core area to reduce price differences in the country.
\end{abstract}

Keywords: commodities, differential, infrastructure, intra-country, price, productivity, remoteness, spatial, trade

\section{Introduction}

It is generally believed that competitive and functioning markets deliver improved welfare to consumers since competition tends to enhance quality and lower prices. In addition functional and well integrated markets enable the flow of commodities from surplus production areas to deficit ones, hence improving people's access to food commodities. It is the improvements in the quality of products and services that translate into micro or household level welfare progresses while lower prices in turn enable households to stretch their incomes further over consumption and time.

In the absence of well-functioning markets and presence of binding constraints to domestic trade, we often witness wide ranging degrees of accessibility to commodities and services, and differentials in their prices in diverse parts of the same country. Dysfunctional markets may be due to a wide range of limitations such as poor infrastructure, lack of timely information, legal impediments, logistical and other transaction bottlenecks, among others. Literature addressing the institutional constraints to market development exist (see for example Fafchamps 2004 and Platteau 2000a, 2000b). Moreover there is empirical evidence of commodity price variability across space and seasons in many developing countries, with significant unexploited arbitrage opportunities underscoring the low level of market integration (Abdulai 2007 and Fackler and Goodwin, 2001).

In the absence of binding constraints to the flow of trade in the country, there should not be significant differentials in the prices of food save the cost of transportation, transaction costs, storage and other overheads. Easy access to larger markets across the country can constitute a strong motivation for increased domestic production. Mosera, Barret and Mintec (2009) have observed that without access to wider national market to absorb excess local supply, there will be no incentive to increase production as this will only lead to lowering "farm-gate" prices. Lower farm-gate prices will in turn act as a disincentive to increased production and technological innovation in the agricultural production sector. In the case of Uganda, the removal of barriers and subsequent integration of domestic markets could significantly contribute to the realization of the objectives of the National Development Plan (NDP) and the Agriculture sector targets of higher productivity, 
commercialization and improved household welfare.

The flow of Uganda's internal trade however seems hampered, with surpluses in certain areas and deficits in others. This uneven spatial accessibility to food commodities and the associated price differences that arise, needs to be addressed through appropriate policy measures to enable the free flow from production zones to consumption destinations in the country. Specifically, a vibrant domestic trade can alleviate artificial spatial commodity shortages in the country by enhancing accessibility to commodities produced in other parts of the country. It is against this background that this paper seeks to identify and evaluate the underlying factors that influence food price differentials (the level of market efficiencies) across different districts in Uganda. In doing so, the paper identifies the constraints to the free flow of internal food commodity trade.

\section{Material and Methods}

\subsection{Review of Literature}

There is a vast bibliography on the measurement of spatial market integration and price differentials. Market efficiency and integration are necessary in the effective transmission of price incentives in the market. Theory predicts that in well integrated and efficient markets, the same commodity should trade at the same price except for the associated transaction costs. This assertion is often referred to as the "Law of One Price" (Persson, 2008 and 1998). The single price is attained through the exploitation of arbitrage opportunities presented by spatial or temporal commodity price variabilities. On the other hand, the excessive variability of prices tends to reflect the lack of spatial market integration usually due to constraints such as inadequate transport infrastructure, lack of storage facilities, imperfect competition and institutional weakness in credit and risk management, and inefficient flow of information (Rashid and Minot, 2010).

Markets can be integrated spatially (over space or locations) or vertically (along a supply chain). Studies such as Gonzalo, Enrique and Lacovone, (2012) and Rashid and Minot (2010) have examined this phenomenon and its role in price transmission in the market. Functional and competitive markets are believed to foster optimal resource allocation, better quality goods and services, and lower prices for consumers. Efficient and integrated markets enable the flow of commodities from areas of plenty to areas of scarcity, thereby ensuring accessibility to goods and services at competitive prices. This linkage between two or more markets causes prices to move in tandem such that changes in prices in one market are mirrored by changes in prices of similar goods in another that is linked to the former through trade (Barrett, 2005). On the other hand, market efficiency refers to the level of costs associated with transactions in matching supply with demand. There are two main categories of market efficiency namely; exchange or arbitrage efficiency which refers to the situation where there are no unexploited opportunities for arbitrage, and operational efficiency referring to the situation where transfer costs cannot be reduced any further than their prevailing levels (Rashid and Minot 2010).

Several studies explain how given constraints determine the price variabilities across regions. Mosera et al. (2009) use a data set that includes rice price data across four quarters along with data on transportation costs and infrastructure availability for nearly all of the 1,394 communes in Madagascar. They test the extent to which markets are integrated across space and compare results across different spatial scales of analysis to explain some of the factors that limit spatial arbitrage and price equalization within a country. Abdulai (2007) explains that spatial price transmission involves how prices between spatially separated markets in a country are related citing the factors that affect this phenomenon. Accordingly, transport and distribution costs play a significant role in spatial price differentials. Gonzalo et al., (2012) investigate the determinants of price differences and market integration among Indonesian provinces and conclude that price differences across provinces respond to differences in provincial characteristics such as remoteness, transport infrastructure, output of the commodity, land productivity and income per capita.

In Uganda there are no specific studies on determinants of spatial price variabilities, although a few address constraints to movement of commodities and the impact of volatile prices. They emphasize the patterns in food price evolution that have changed since 2008 (see for example Benson, Mugarura and Wanda, 2008; Mbowa, Mawejje and Kasirye, 2012 and Campenhout, Pauw and Minot, 2013). They argue that high food production districts (regions) tend to have lower and relatively more stable prices as compared to the low producers. The literature summarizes factors that impede intra-country trade and therefore constitute constraints that need to be addressed to act as incentives to increase agricultural production and productivity. This glaringly demonstrates that intra district or regional trade impediments in Uganda have not been addressed adequately which this study seeks to contribute to. 


\subsection{Analytical Framework}

Theory suggests that the same commodity should trade at the same price in efficient and well integrated markets except for transportation and other transactions costs. A corollary to the law of one price further predicts that given well-functioning markets, spatial variabilities are only transitory since this would offer opportunities for arbitrage which if exploited will drive the system back to the one price equilibrium state. This is often expressed as in equation (1) (Persson, 1998):

$$
p_{j}=p_{i}+t_{i j} \ldots \ldots \ldots \ldots
$$

Where $p_{j}$ is the price of the commodity in location $j, p_{i}$ is the price in location $i$, and $t_{i j}$ is the transport and transactions costs over location $i$ and $j$. It is hypothesized that if the difference between $p_{j}$ and $p_{i}$ exceeds $t_{i j}$, then the ratio is greater than one which acts as an incentive to rational and well-informed traders to take advantage to make profits by moving the commodities from regions with excess to those with relative scarcity. Eventually the gap between the two regions closes, hence one price.

\subsection{The Estimation Model}

Following from Gonzalo et al. (2012), spatial price differentials is modelled for selected commodities using price, infrastructure, crop yield per acre, population and welfare data in the respective districts. In an ideal situation, the price difference for a commodity between two locations (in this respect district $i$ and $j$ ) will either be less or equal to the relevant trade costs, $t$ as expressed in equation (2):

$$
\left|p_{i}-p_{j}\right| \leq t
$$

It is expected that the absolute difference between the prices in district $i$ and $j$ is lower or equal to the transportation and distribution costs, $t$. The costs play a significant role in determining the magnitudes of the difference among districts. For example, if the price of a commodity due to the interaction of supply and demand forces in district $j$ is well above that in district $i$ plus the cost associated of transport from district $i$, then producers will send their commodity to district $j$ and the price in district $j$ will be expected to eventually go down. However if the initial difference is lower than the transportation cost then there will be no incentive for producers in district $i$, to transport the commodity to district $j$. Other factors that can potentially influence commodity price differences between two different locations include labor productivity, cost of inputs such as capital and land, weather conditions, consumer purchasing power and population of the districts concerned. These factors are captured in the model to examine their role as drivers of commodity price differentials between two districts, $i$ and $j$. We specify the following model in equation (3) as used by Gonzalo et al., (2012):

$$
\begin{aligned}
& \left\lfloor p_{i}-p_{j}\right\rfloor=\beta_{0}+\beta_{1} \operatorname{Re}_{i}+\beta_{2} \operatorname{Re}_{j}+\beta_{3} \operatorname{Re}^{*} \operatorname{Inf}_{i}+\beta_{4} \operatorname{Re}^{*} \operatorname{Inf}_{j}+\beta_{5} C_{i j}+\beta_{6} \operatorname{Pr}_{i}+\beta_{7} \operatorname{Pr}_{j}+\beta_{8} P C_{i}+ \\
& \beta_{9} P C_{j}+\beta_{10} P C I_{i}+\beta_{11} P C I_{j}+\beta_{12} R C+\beta_{13} R E+\beta_{14} R N+\beta_{15} R W+e_{i j} \text {. }
\end{aligned}
$$

Where:

a) $P_{i}-P_{j}$ is the price difference between district $i$ and $j$ measured in shillings;

b) $R e_{i}$ and $R e_{j}$ is the distance of district $i$ or $j$ to the nearest municipality weighted by the inverse of the population and multiplied by the cost of fuel, which is meant to control for transportation costs. A higher weighted distance increases transport costs and therefore increases the price difference. It is a measure of remoteness on price differentials to the extent that reducing the distance reduces the difference, hence a negative effect.

c) $R * \operatorname{Inf} f_{i}$ and $R * \operatorname{Inf} f_{j}$ is road density per district $i$ and $j$. It is expected that distance affects the price the more when the quality of transport infrastructure is worse. A higher density lowers the price difference implying that it has a negative effect. This variable is interacted with distance in the model.

d) $\mathrm{Co}_{i j}$ is a dummy variable that takes value one if the two districts share a border and zero otherwise (contiguity). It is meant to capture proximity of districts in relation to transport costs. It is expected to have a negative effect since closeness/proximity of districts reduces the cost of transactions.

e) $P r_{i}$ and $P r_{j}$ stand for supply conditions measured by unit yield (productivity) of output of the commodities. Improvement in the supply condition will therefore have a negative effect on the price difference since it will reduce it. 
f) $P C_{j}$ and $P C_{i}$ is the level of output of the commodity normalized by the population in the district. According to Goodwin and Schroeder (1991), low volume markets have "a bigger potential for exhibiting unwarranted price behaviour". In this case, high production will even the price across; and lower production will increases it. Therefore output level will have a negative sign impac.

g) $P C I_{i}$ and $P C I_{i}$ is consumption expenditure as proxy for welfare which captures demand-push effects across district. If the $P C I_{i j}$ effect is present, a negative coefficient will be observed since high incomes will tend to increase demand and therefore even the price.

h) The regional dummies $R C_{i j}$ (Central region), $R E_{i j}$ (Eastern region), $R N_{i j}$ (Northern region), and $W N_{i j}$ (Western region) demonstrate the price differences across the regions and implicitly the impact of the different constraints.

i) $e_{i j}$ is an error term capturing all other factors.

\subsection{The Types and Data Sources}

The paper draws on data from several sources which include household surveys/census conducted by the Uganda Bureau of Statistics (UBoS): the Uganda Census of Agriculture (UCA) in 2008/9, which covered the then 80 districts for two crop growing seasons. The estimated number of agricultural households was 3.95 million which constituted 19.3 million persons. Crop yields were computed from the Crop Module whereas milk yields were from the Livestock Module. The average consumption expenditure at district level used as a proxy for welfare is based on the Uganda National Household Survey of 2009/10. The other sources include administrative data on: population projections and area in square kilometres from UBoS Statistical Abstracts (2008 and 2009). Density was computed from the road length data from the Ministry of Works and Transport. The data is a cross section for two farming seasons.

\section{Results and Discussions}

Table 1 presents significant crop production variations for the commodities of interest across regions. Whereas eastern Uganda is the largest producer of maize, sweet potatoes and millet, western is the largest producer of bananas. This pattern is closely followed by the yields and the percentage distribution of the crops among the regions.

Table 1 . Annual crop production, productivity and percentage distribution by region, 2008/2009

\begin{tabular}{|c|c|c|c|c|}
\hline Regions & Maize & Bananas & Sweet Potatoes & Millet \\
\hline \multicolumn{5}{|c|}{ Production in tonnes } \\
\hline Central & 449859 & 929534 & 312402 & 13734 \\
\hline Eastern & 1,108554 & 333851 & 847140 & 106838 \\
\hline Northern & 305798 & 26015 & 292932 & 78572 \\
\hline Western & 497745 & 2728587 & 366295 & 77784 \\
\hline National & 2361956 & 4017986 & 1818769 & 276928 \\
\hline \multicolumn{5}{|c|}{ Yield -tonnes per acre } \\
\hline Central & 2.4 & 3.3 & 3.2 & 2.4 \\
\hline Eastern & 2.9 & 5.6 & 5.3 & 1.2 \\
\hline Northern & 1.2 & 5.1 & 4.8 & 0.7 \\
\hline Western & 2.6 & 6.0 & 3.0 & 1.5 \\
\hline National & 2.3 & 5.0 & 4.1 & 1.1 \\
\hline \multicolumn{5}{|c|}{ Percentage distribution } \\
\hline Central & 19.0 & 23.1 & 17.2 & 5.0 \\
\hline Eastern & 46.9 & 8.3 & 46.6 & 38.6 \\
\hline Northern & 12.9 & 0.1 & 16.1 & 28.4 \\
\hline Western & 21.1 & 67.9 & 20.1 & 28.1 \\
\hline National & 100 & 100 & 100 & 100 \\
\hline
\end{tabular}

Source: calculations based on UCA 2008/9 data. 
Given that not all produce is sold on the market but partially consumed by households (subsistence), ie, retained, it is important to establish proportions for either use. Figure 1 illustrates the proportions sold on the market giving an indication of the level of market development for each crop. The statistics reveal that maize (41\%) is the most sold commodity, followed by bananas (35\%), millet (19\%) and sweet potatoes $12 \%$. This suggests that households largely grow crops for subsistence and have not significantly ventured into production for the market for various reasons. This echoes the limited commercialization of agriculture in Uganda.

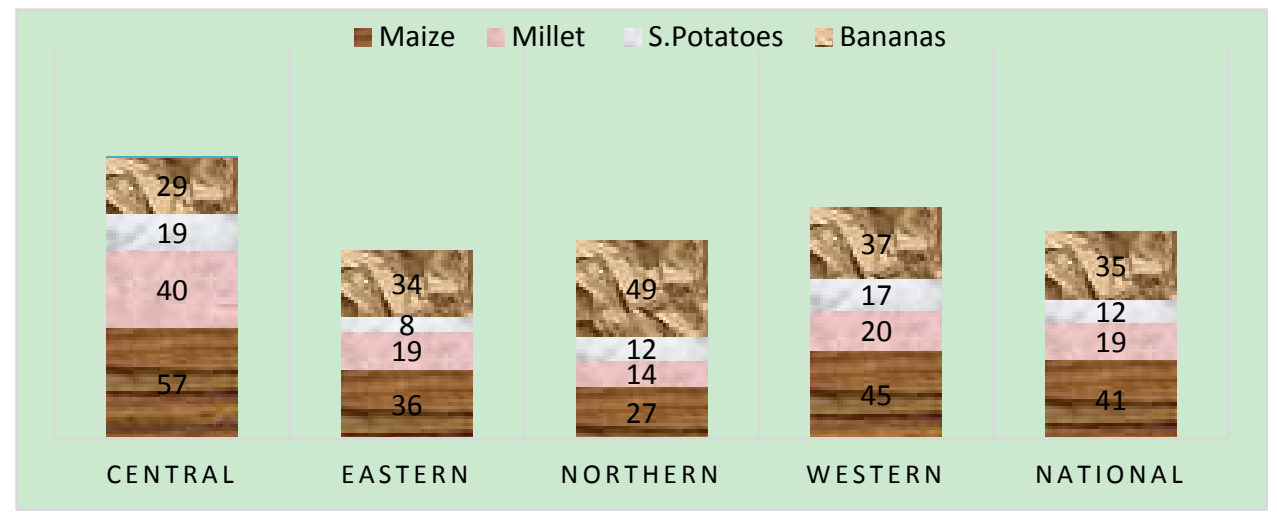

Figure 1. Share of crop production sold after harvest by region, (\%)

Source: calculations were based on UCA 2008/9 data

Table 2 presents the average commodity price giving an indication of the transaction and distribution costs between two respective regions/districts. The spatial price differentials thus implicitly suggest the magnitudes of the constraints that exist and bar the even distribution in the country. It is evident that significant differences in average prices do exist. Specifically, average prices are higher in the least developed region (Northern) and lower in the most developed region (Central) in Uganda.

Table 2. Average prices for the selected food commodities at regional level (UShs/kg) in 2008/9

\begin{tabular}{lrrrrr}
\hline Region & Maize & Bananas & S potatoes & Millet $^{\mathrm{a}}$ & Milk $^{\mathrm{b}}$ \\
\hline Central & 261 & 261 & 395 & 1,848 & 428 \\
Eastern & 422 & 422 & 325 & 1,562 & 459 \\
Northern & 533 & 551 & 405 & 1,623 & 517 \\
Western & 367 & 367 & 353 & 1,691 & 355 \\
National & 396 & 400 & 370 & 1,681 & 442 \\
\hline
\end{tabular}

Source: calculations were based on UCA, 2008/9.

Notes: ${ }^{a}$ Due to data limitations, the price of millet flour was used as a proxy for that of finger millet

${ }^{b}$ average price of milk is per litre.

Regions that produce the largest quantities have the least average prices. The exception is the central region for maize, largely explained by Kampala being the major trading centre sometimes attracting competition thus lowering the price. Furthermore, maize is one of the main staple foods with the largest proportion marketed out of the total production quantities. As illustrated in a panel of Figures 2, the relationship between the average prices and the output in the districts is intuitively inverse. 

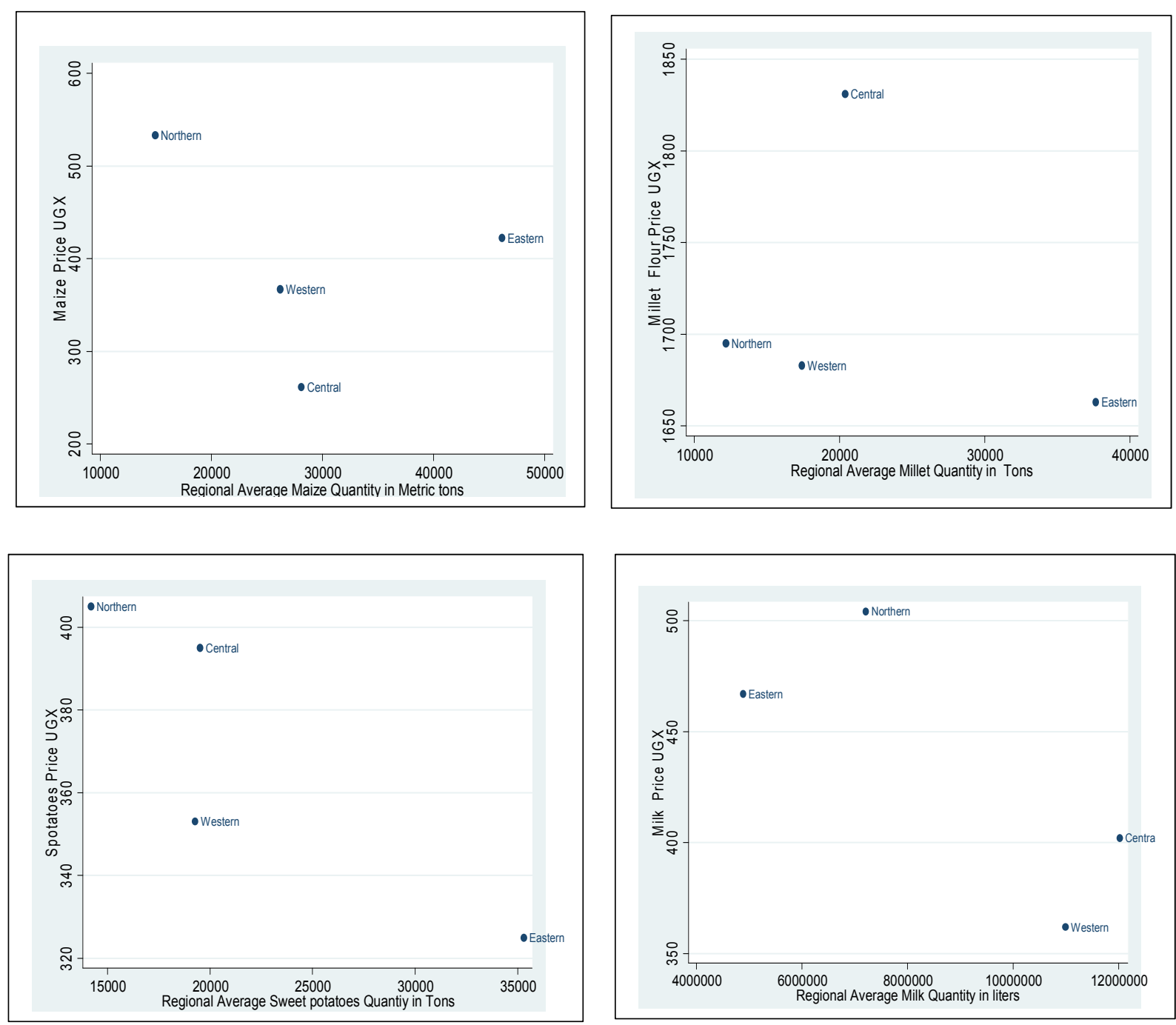

Figure 2. The relationship between average crop prices and output at regional level, 2008/2009

Source: calculations were based on the UCA data 2008/9.

This further strengthens the inclusion of the production capacities in the analysis as it determines the initial price difference between districts. The panel of figures further illustrates the spatial differences in prices of individual commodities based on regions. For example, the western region, which is the main producer of bananas, has the lowest price and the rest of the regions are higher. It is evident that the average prices are likely to be lower the higher the production and yield levels. This suggests that in the domestic market, price differentials are exacerbated by production and storage capacities in addition to transport costs and transaction constraints.

Although Uganda's internal trade is facilitated by road, rail, inland water and air transport, much of the movement of agricultural commodities is carried out by road. In 2008, Uganda's road network was estimated to comprise a total of $78,100 \mathrm{~km}$ of which $10,800 \mathrm{~km}$ were national , 27,500 km were district , 4,800 km were urban and 35,000 km were community (Uganda National Road Authority, 2008). In 2011, the total length of paved road was estimated at 3,264 km (UBoS, 2012), representing approximately 30 percent of the "national" category. The central region has the highest average length of $423 \mathrm{~km}$ followed by western $362 \mathrm{~km}$, northern $274 \mathrm{~km}$ and finally eastern $212 \mathrm{~km}$. However, in terms of road density, the Central region is far above the rest with $0.6 \mathrm{~km}$ per square kilometre followed by eastern and western with $0.2 \mathrm{~km}$ per square kilometre and finally northern $0.1 \mathrm{~km}$ per square kilometre. It is evident that infrastructural development as measured by road density follows the region's level of development. The low density for northern Uganda is not surprising after two decades of conflict resulting into minimum development. Thus, the transportation of commodities tends to be 
slower due to a host of factors.

Table 3 presents econometrics results by commodity (maize, bananas, millet, milk and sweet potatoes). The average price difference between district $i$ and district $j$, during 2008/9, is estimated to establish the effect of a number of covariates.

Table 3. Determinants of cross district price differentials for five commodities

\begin{tabular}{|c|c|c|c|c|c|}
\hline & Maize & Bananas & Milk & Potatoes & Millet \\
\hline \multirow[t]{2}{*}{ border } & $-102.4 * * *$ & $-109.5^{* * *}$ & $-43.35 * * *$ & $-42.83 * * *$ & $-95.96 * * *$ \\
\hline & -5 & -5.133 & -7.25 & -2.457 & -6.05 \\
\hline \multirow[t]{2}{*}{ Remote $_{i}$} & 10.83 & 2.299 & $51.24 * * *$ & $-17.73 * * *$ & $-56.67 * * *$ \\
\hline & -5.7 & -5.89 & -7.47 & -2.86 & -6.94 \\
\hline \multirow[t]{2}{*}{ Remote $_{j}$} & 5.545 & 0.55 & $55.73 * * *$ & $-23.30 * * *$ & $-63.04 * * *$ \\
\hline & -5.835 & -6.04 & -7.63 & -2.94 & -7.07 \\
\hline \multirow[t]{2}{*}{ Remote $*_{i n f}$} & $-118.7 * * *$ & $-130.8 * * *$ & $-119.2 * * *$ & $112.0 * * *$ & $891.3 * * *$ \\
\hline & -18.96 & -19.69 & -25.94 & -9.33 & -22.9 \\
\hline \multirow[t]{2}{*}{ Remote ${ }^{*} i n f_{j}$} & $-106.5^{* * *}$ & $-94.31 * * *$ & $-143.1 * * *$ & $116.7 * * *$ & $903.8^{* * *}$ \\
\hline & -19.23 & -19.81 & -26.21 & -9.45 & -23.17 \\
\hline \multirow[t]{2}{*}{ Yield $_{i}$} & $-2.718 * * *$ & $-0.75 * *$ & $-1.335^{* *}$ & $-0.32 *$ & $4.387 * * *$ \\
\hline & -0.473 & -0.262 & -0.469 & -0.13 & -1.216 \\
\hline \multirow[t]{2}{*}{ Yield $_{j}$} & $-2.299 * * *$ & -0.44 & $-1.395 * *$ & $-0.84 * * *$ & $4.516^{* * *}$ \\
\hline & -0.486 & -0.27 & -0.472 & -0.132 & -1.247 \\
\hline \multirow[t]{2}{*}{ Output $_{i}$} & $-0.23 * * *$ & $-0.03 *$ & -0.034 & 0.00 & $-0.36^{* *}$ \\
\hline & -0.021 & -0.012 & -0.036 & -0.015 & -0.12 \\
\hline \multirow[t]{2}{*}{ Output $_{j}$} & $-0.22 * * *$ & $-0.052 * * *$ & -0.053 & $0.03 * *$ & $-0.37 * *$ \\
\hline & -0.0215 & -0.01 & -0.04 & -0.01 & -0.126 \\
\hline \multirow[t]{2}{*}{ PCIi } & $-57.03 * * *$ & $-63.97 * * *$ & 13.58 & $-44.99 * * *$ & $55.85 * * *$ \\
\hline & -4.34 & -4.536 & -7.65 & -2.15 & -5.23 \\
\hline \multirow[t]{2}{*}{$P C I_{j}$} & $-69.64 * * *$ & $-58.71 * * *$ & $72.81 * * *$ & $-18.93 * * *$ & $67.35^{* * *}$ \\
\hline & -5.502 & -5.64 & -9.002 & -2.704 & -6.68 \\
\hline \multirow[t]{2}{*}{ Central } & - & 5.45 & - & - & - \\
\hline & - & -4.96 & - & - & - \\
\hline \multirow[t]{2}{*}{ Eastern } & $-22.35^{* * *}$ & $-23.29 * * *$ & $14.52 *$ & -1.03 & $-27.86^{* * *}$ \\
\hline & -3.86 & -3.65 & -5.72 & -1.87 & -4.71 \\
\hline \multirow[t]{2}{*}{ Northern } & $-16.59 * * *$ & . & $74.69 * * *$ & $40.82 * * *$ & $14.81^{*}$ \\
\hline & -4.75 & . & -6.92 & -2.336 & -5.81 \\
\hline \multirow[t]{2}{*}{ Western } & $-13.97 * * *$ & -2.70 & 0.35 & $5.21 * *$ & $-25.35^{* * *}$ \\
\hline & -3.83 & -4.17 & -5.71 & -1.878 & -4.58 \\
\hline \multirow[t]{2}{*}{ _cons } & $1580.2^{* * *}$ & $1513.9^{* * *}$ & $-784.2 * * *$ & $752.4 * * *$ & $-1195.7 * * *$ \\
\hline & -77.09 & -77.46 & -127.2 & -38.13 & -93.56 \\
\hline $\mathrm{r} 2$ & 0.129 & 0.108 & 0.0617 & 0.132 & 0.321 \\
\hline
\end{tabular}

Notes: The figures above are coefficients and below are the standard errors; level of significant $* \mathrm{p}<0.05,{ }^{* *}$ $\mathrm{p}<0.01,{ }^{* * *} \mathrm{p}<0.001 ;$ Prob $>\mathrm{F}=0.000$; Observations: crops $=12,324$ and milk 6,162. 
The results for contiguity for all the commodities are highly significant and with the correct signs (negative) suggesting closeness between the districts reduces the price differentials. In essence proximity reduces transport and distributional costs. Remoteness exhibits different patterns and does not show significance for maize and bananas. For sweet potatoes, milk and millet it is significant and negative conforming to the a priori expectations. Largely, the results suggests that price difference is increased by remoteness. The results are improved when we interact the impact of remoteness with infrastructure in especially rural areas which highlights the deficiencies in rural infrastructure.

The paper adopts road density as a proxy for infrastructural development at the district level, although this should encompass, all sorts of infrastructure in rural areas such as: valley dams, irrigation, disease control facilities, research, markets, agro-processing infrastructure among others. All the commodities reveal negative significant coefficients suggesting that the interaction of remoteness and poor infrastructure is likely to increase the price difference. It is intuitive since bananas and milk especially, are highly perishable commodities that require an efficient system to be moved from points of production to points of marketing and consumption. The results suggest interesting patterns: remote and infrastructure deficient districts pay higher prices than their counterparts.

Productivity (yield) differences do affect the price differential of the commodities significantly. Improving the yield capacity for maize, bananas, millet, sweet potatoes and milk would greatly lower the price difference among the different districts in Uganda. For these commodities, the policy approach should be to increase yield per acre (per cow for cattle) through use of improved varieties/breeds and use of better inputs.

The output per capita of the commodity significantly affects the price differences. Districts that produce more maize, bananas, sweet potatoes and milk relative to their population face a lower price for the product. This suggests that the difference for these commodities between producing districts and consuming districts is quite high. This is in agreement with the findings of Mbowa et al. (2012) and Benson et al. (2008) that emphasised the role of productive capacities of districts. Uganda has a lot of unutilized arable land that can help expand commodity production. The limiting fact has been partly inadequate mechanization in form of tractors that can enhance opening of large areas of land. Therefore, high price differentials among districts can be reduced and opportunities for arbitrage can be exploited if commodity production is expanded through opening new areas and increase yield per hectare/cow.

The effect of differences in quantities consumed associated with per capita income is dominated by all the commodities as their coefficients are negative and significant. These results suggest that as households increase their income, the resultant effects is a lower price difference among the districts. Increase in income increases the demand for the commodities triggering demand in the deficient districts leading to more or less even distribution of the commodities hence a lower price difference.

The regional dummies (central, western, northern and eastern) included in the analysis reveal that districts belonging to a region have high chances of lowering the price differentials. This is a consequence of the constraints to movement of food commodities which further strengthens the factors so far discussed. It is notable that central Uganda does not show any significance. This can be explained by seasonal variations among the others regions that supply the centre a major market for food commodities which maintains an even price throughout the time.

Overall, the results resonate with similar studies done elsewhere as presented in the literature review section. Remoteness, infrastructure status, production capacities and welfare status do influence the degree of price differentials in Uganda. The is reflected in the studies by Mosera et al. (2009) and Abdulai (2007), who explain the determinants of spatial market differentials. Furthermore, the model as developed by Gonzalo with limited modification explains the existing constraints to movement of food commodities across the districts in Uganda.

\section{Conclusions and Policy Implications}

In this study the determinants of price differentials in Uganda were studied, using detailed price data covering 79 districts for two seasons of 2008/9, to shed some light on the drivers. In a context where commodity prices have been changing, this study is particularly relevant for a country that is resource endowed but limited by infrastructure and other rigidities in order to understand what drives the phenomenon of plenty in some districts and scarcity in others. The extraordinarily uneven distribution of commodity prices across the country is partly explained in this study. It is anticipated that this will allow the government to take appropriate measures to enable farmers/producers take optimal production decisions and traders to reach out to the entire country. Moreover, it will allow the government to better target its policies geographically to mitigate the impact of a particular price shock on the poor population. 
By focusing on the determinants of price differences among districts some consistent findings irrespective of the commodity analysed were observed. The interaction between remoteness and quality of infrastructure clearly influence price differentials. Remote towns pay a higher price, but the effect is attenuated by good transport infrastructure. Furthermore, price differences are also significantly explained by output, per capita income and land productivity. Notably, income per capita at the same time captures unobserved quality differences across districts as well as development and local production capacities.

In conclusion the study points towards two important policy implications: first, it confirms the importance of investing in infrastructure illustrating that the constraints generated by geography and remoteness can be alleviated. This can be achieved through improvements in the investment climate and investment in public works. Second, the importance of strengthening the capacities of farmers and their productivity as an important means not only to improve their livelihoods but also as an instrument to foster more efficient markets with faster supply responses to changes in prices.

\section{References}

Abdulai, A. (2007). Spatial and Vertical Price Transmission in Food Staples Market Chains in Eastern and Southern Africa: What Is the Evidence? Paper presented to FAO Workshop on Staple Food Trade and Market Policy Options for Promoting Development in Eastern and Southern Africa, Rome. Barrett, C., 1994.

Barett, B. C. (2005). Entry. In L. E. Blume, \& S. N. Durlauf (Eds.), The New Palgrave Dictionary of Economics (2nd ed.). London, Palgrave Macmillan.

Beson, T., Mugarura, S., \& Wanda, K. (2008). Impacts in Uganda of rising global food prices: the role of diversified staples and limited price transmission. IFPRI Uganda Country Office.

Blanchard, O. (1997). The Economics of Post-Communist Transition. New York: Oxford University Press.

Campenhout, B. J., Pauw, K., \& Minot, N. (2013). The Impact of Food Price Shocks in Uganda First-Order versus Long-Run Effects, IFPRI Discussion Paper 01284 Development Strategy and Governance Division.

Fackler, P., \& Goodwin, B. K. (2001): Spatial Price Analysis. Chap. 17 in Handbook of Agricultural Economics Vol.1, Ed. by B.Gardner and G. Rausser, pp. 971-1024. Elsevier Science, Amsterdam.

Fafchamps, M. (2004). Market Institutions in Sub-Saharan Africa: Theory and Evidence. The MIT Press, Cambridge.

Gonzalo, V., Enrique, A. C., \& Lacovone, L. (2012). Determinants of Market Integration and Price Transmission in Indonesia, World Bank East Asia and Pacific Region Poverty Reduction and Economic Management Unit, Policy Research Working Paper 6098.

Goodwin, B. K., \& Schroeder T. C. (1991). Co-integration tests and spatial price linkages in regional cattle markets. American Journal of Agricultural Economics, 73(2), 452-464. http://dx.doi.org/10.2307/1242730

Mbowa, S., Mawejje, J., \& Kasirye, I. (2012). Understanding the Recent Food Price Trends in Uganda, EPRC Fact sheet No. 4.

Mosera, C., Barrett, C., \& Mintenc, B. (2009). Spatial integration at multiple scales: rice markets in Madagascar. Agricultural Economics, 40, 281-294. http://dx.doi.org/10.1111/j.1574-0862.2009.00380.x

Persson, K. G. (1998). Grain Markets in Europe, 1500-1900: Integration and Deregulation. Cambridge, Cambridge University Press.

Persson, K. G. (2008). Law of One Price. Retrieved from http://eh.net/encyclopedia/article/persson.LOOP

Platteau, J. P. (2000a). Institutions, Social Norms, and Economic Development. Harwood Academic Publishers, New York

Platteau, J. P. (2000b). Institutions, Social Norms and Economic Development. Overseas Publishers Association, Amsterdam.

Rashid, S., \& Minot, N. (2010). Are Staple Food Markets in Africa Efficient? Spatial Price Analyses and Beyond. Paper Presented at COMESA Conference 25-26 January 2010. Maputo.

Taylor, A. M. (2001). Potential Pitfalls for the Purchasing Power Parity Puzzle? Sampling and Specification Biases in Mean-Reversion Tests of the Law of One Price. Econometrica, 69(2), 473-98. http://dx.doi.org/10.1111/1468-0262.00199

Uganda Bureau of Statistics. (2010). Uganda Census of Agriculture 2008/2009: Volume IV - Crop Area and 
Production Report. Kampala, Uganda Bureau of Statistics. December 2010.

Uganda National Roads Authority. (2008). Uganda National Transport Master Plan (NTMP) and Greater Kampala Metropolitan Area Transport Master Plan. Kampala Uganda.

\section{Copyrights}

Copyright for this article is retained by the author(s), with first publication rights granted to the journal.

This is an open-access article distributed under the terms and conditions of the Creative Commons Attribution license (http://creativecommons.org/licenses/by/3.0/). 